Article

\title{
Innovative Business Model for Realization of Sustainable Supply Chain at the Outsourcing Examination of Logistics Services
}

\author{
Péter Tamás \\ Institute of Logistics, Faculty of Mechanical Engineering and Informatics, University of Miskolc, \\ 3515 Miskolc-Egyetemváros, Hungary; tamas.peter@uni-miskolc.hu; Tel.: +36-70-409-5713
}

Received: 29 December 2017; Accepted: 15 January 2018; Published: 16 January 2018

\begin{abstract}
The issue of sustainability is becoming more and more important because of the increase in the human population and the extraction of non-renewable natural resources. We can make decisive steps towards sustainability in the fields of logistics services by improvement of logistics processes and/or application of new environment-friendly technologies. These steps are very important for companies because they have a significant effect on competitiveness. Nowadays significant changes are taking place in applied methods and technologies in the fields of logistics services as part of the 4th Industrial Revolution. Most companies are not able to keep pace with these changes in addition to carrying out their main activities by using own resources; consequently, in many cases logistics services are outsourced in the interest of maintaining or increasing competitiveness. The currently applied outsourcing examination process contains numerous shortcomings. We have elaborated a new business model to eliminate these shortcomings, namely the basic concept for an outsourcing investigation system integrated in the electronic marketplace. The paper introduces the current process of logistics service outsourcing examination and the elaborated business model concept.
\end{abstract}

Keywords: sustainability; outsourcing; investigational method

\section{Introduction}

Nowadays Industrial Revolution 4 is taking place, with its objective being the realization of unique product manufacturing with mass production's efficiency [1]. This aim seems futuristic, but the necessary tools are already available (Internet of Things, Big Data, cyber-physical systems) [2]. The increase in the human population and industrial efforts to satisfy unique customer needs has resulted in growth in the extraction of natural resources; consequently, the issue of sustainability has become increasingly important [3,4]. The literature defines sustainability as satisfaction of the current needs of humanity besides conservation of the environment and natural resources for future generations [5].

We can make significant efforts to attain sustainability with improvement of logistics processes and/or application of environment-friendly technologies in the fields of logistics services. The application of the lean principles and methods is one of the most important tools in process improvement. This tool enables the elimination of wastes in the logistics processes, meaning that we can perform the same logistics activities with fewer natural resources and a lower environmental burden [6-8]. We can achieve the same effects through application of environment-friendly technologies using significant financial investments (environment-friendly vehicles and packaging materials, using renewable energy resources to operate facilities, etc.).

The literature analyzes supply chains in several directions, with the most important being the importance of the human effects on services [9], the role of uncertainties in supply chain management [10], and research on risk management possibilities [11,12]. 
The literature has not specifically dealt with the outsourcing of logistics services in the aspect of sustainability. However, significant steps can be made towards sustainability through properly executed outsourcing (selecting more efficient logistics processes and/or application of new environment-friendly technologies) [13-15]. To briefly define outsourcing, it is a process that results in transmission of a service from a manufacturing or service company to another company because of lower costs and/or higher service level [16].

This paper introduces the range of outsourceable logistics services, the possible advantages and risks of outsourcing, and the steps of the outsourcing process based on an overview of the literature. Then it discusses the shortcomings of the outsourcing investigation process and presents an improvement possibility, namely the basic concept of an outsourcing investigational system integrated in electronic marketplace.

\section{Outsourcing Possibilities for Logistics Services}

The outsourcing of primary logistics activities has been most frequently realized in case of manufacturing companies and logistics services providers [17]. Primary logistics services include transportation, warehousing, packaging, loading and commissioning activities. In several cases the secondary logistics services (management of inventory, orders, complaints, and sales) and even the tertiary services (consultancy, education, data processing, execution of payment execution) have been outsourced [17]. Other logistics services can be outsourced regarding procurement, production, distribution and recycling logistics subsystems [18].

In addition, there are simple cases of outsourcing examination (when only one logistics service is outsourced) and complex cases (when two or more services are outsourced simultaneously). An example of complex outsourcing is the common outsourcing of warehousing and inventory management activities.

Logistics activity outsourcing can be fully or partially performeded. Figure 1 presents the outsourcing possibilities of logistics activities.

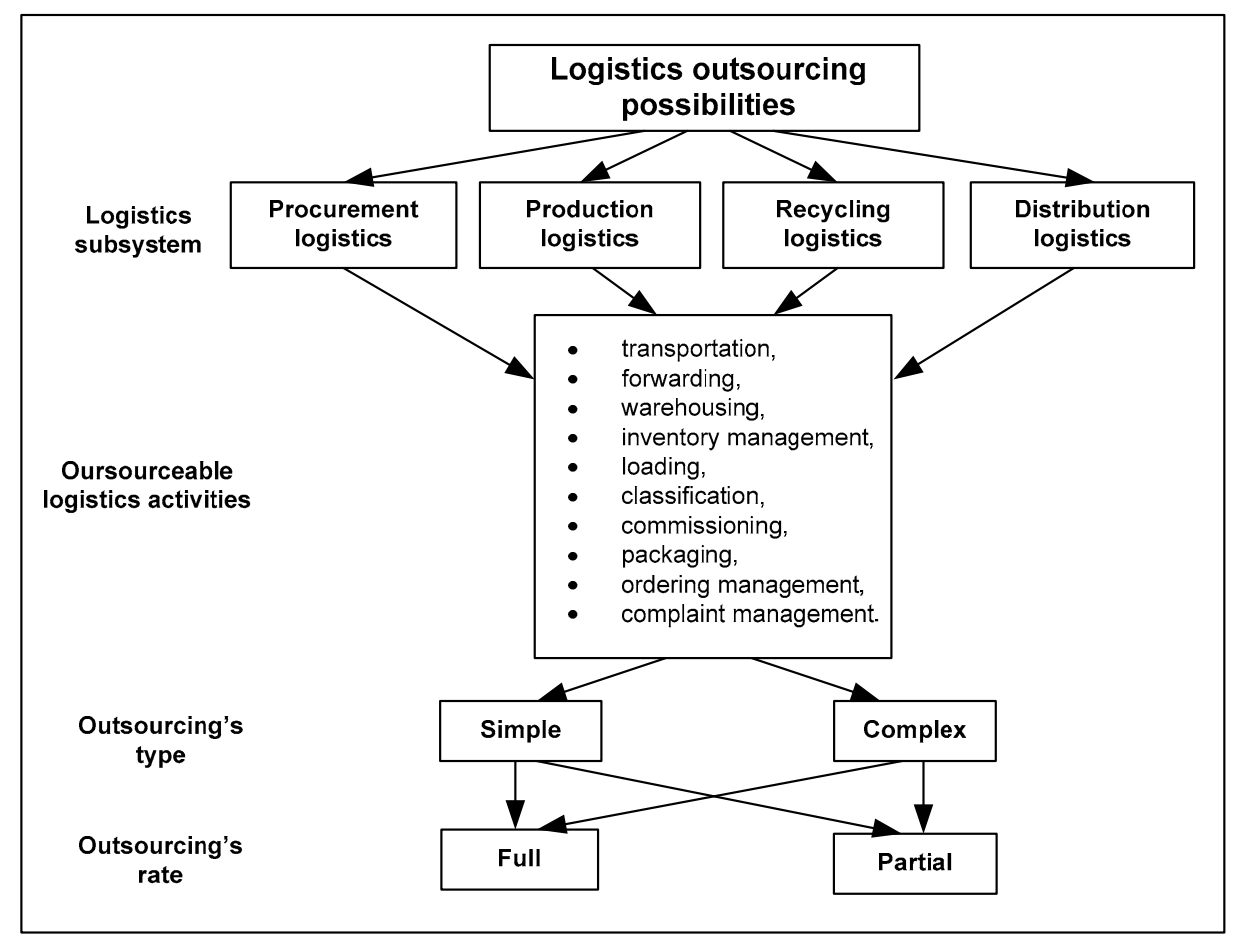

Figure 1. Outsourcing possibilities of the logistics activities. 


\section{Possible Advantages and Risks of Logistics Services}

It is necessary to evaluate the possible advantages and risks of outsourcing before the examination to select the logistics activities to be examined. This section gives an overview about potential benefits and drawbacks.

Possible advantages of outsourcing:

- The outsourced logistics services are performed at lower cost [19]: Usually the logistics service provider carries out its logistics services for several customers and thus the capacity utilization of logistics resources will be higher. The outsourced services' specific cost will be lower in many cases because of economies of scale.

- Increase in the service level [20]: The logistics service providers execute their logistics services as their main activity. These companies continuously improve their services to maintain and/or strengthen their competitiveness. Generally, we can state that the service level will be increased because of the outsourcing.

- Postponement of necessary logistics investments [19]: If a firm does not have the financing for logistics investment (purchasing of environment-friendly vehicles, packaging, unit load forming devices, etc.) then the logistics activities' outsourcing can be a good solution (e.g., product storage can be outsourced in case of lack of storage capacity).

- Use of the created spare capacities for other activities [21]: Outsourcing logistics activities can result in more spare capacity which can be used for other purposes (e.g., we can gain spare storage capacity by outsourcing warehousing activities, and the spare capacity can then be used for production purposes).

- Decrease of failure risks regarding outdated technologies [22]: We can replace outdated technologies through outsourcing the outdated equipment, consequently we can increase the equipment's availability. The risk of technological obsolescence will be decreased because the logistics service providers continuously improve their equipment because of the competition.

- Focusing on the main activity $[17,19,22]$ : The companies' leaders will gain more spare time for the examination and development of their main activities (product or service development, production management, etc.) if other activities are outsourced.

- Decrease in consumption of non-renewable natural resources: Logistics service providers can decrease the amount of consumed non-renewable resources by application of renewable natural resources and more efficient logistics processes.

- Decrease in the environmental burden: The environmental load can be reduced because of outsourcing due to more efficient processes and/or more modern technologies.

Possible risks of outsourcing:

- Insufficient performance [20]: The level of execution of logistics services can drop if the logistics service providers' capacities are not sufficient for carrying out the contracted logistics activities and/or the the activities to be performed are not properly integrated (e.g., the tasks to be performed are not properly standardized).

- Bankruptcy of the logistics service providers or theft of products [23]: The logistics service providers' financial stability and illegal theft of the products can mean significant risk. We need to analyze these risks in the logistics service outsourcing examination.

- Illegal theft of business information [24,25]: We must analyze the possibility of business information being stolen, especially in industrial sectors where this would result in relevant risks (e.g., a competitor can create an inventory management strategy based on the illegal stolen warehousing management information that can be disadvantageous for the customer).

\section{Introduction of the Outsourcing Investigation Process}

The logistics outsourcing process can be standardized based on the international literature $[23,26,27]$ as well as industrial experience $[28,29]$. The process is outlined in Figure 2. 
The outsourcing process can be divided into three parts, namely the outsourcing investigation-, contractual and implementation stages.

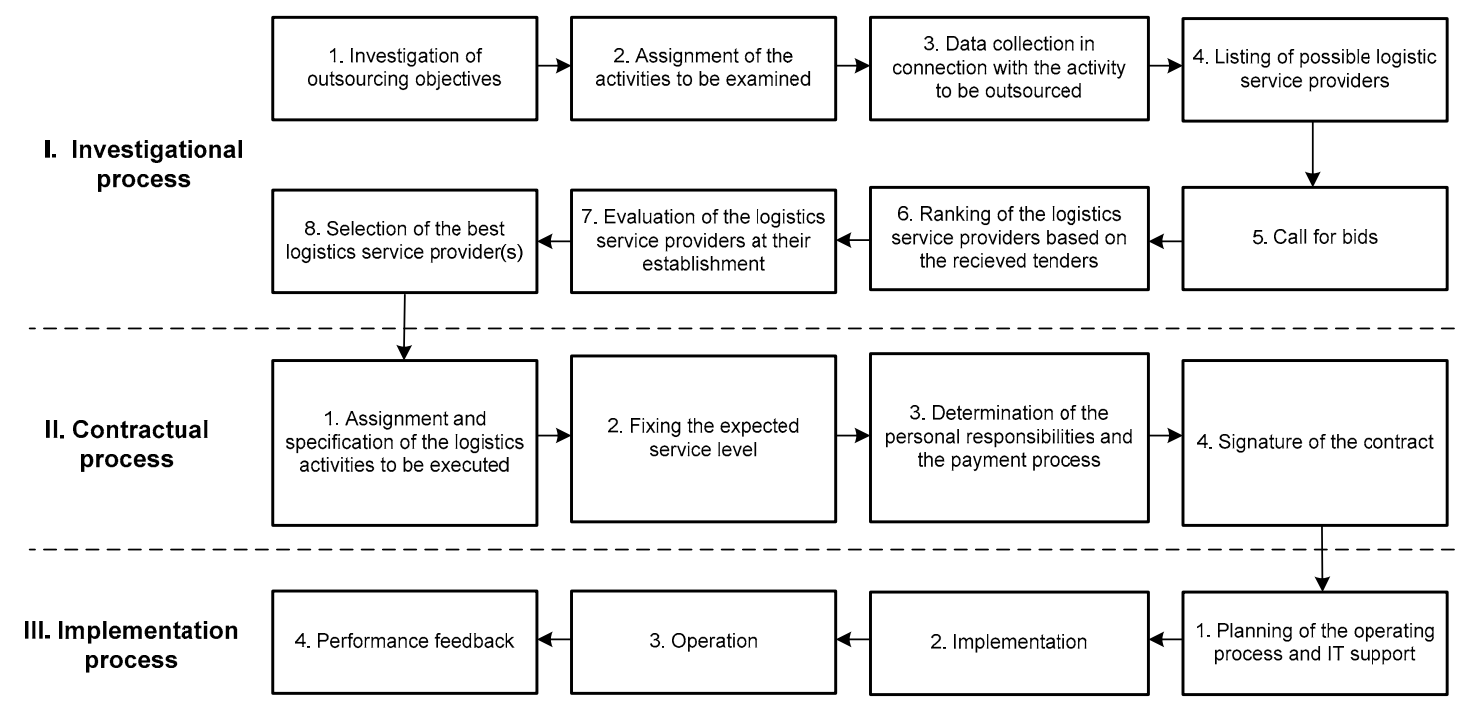

Figure 2. Structure of the outsourcing process.

I. Investigation process: This process lasts from the determination of outsourcing objectives to selection of the best logistics service provider(s). The elements are the following:

1. Determination of outsourcing objectives: The objective is to reach some advantage regarding an assigned logistics area (e.g., reduction of the warehousing costs, increase in reliability of delivery activities, etc.).

2. Assignment of the activities to be examined: The companies determine the logistics activities to be examined based on their logistics objectives (e.g., products' warehousing activities regarding the assigned warehouse).

3. Data collection regarding the activity to be outsourced: The company collects the data that must be provided in a call for bids (e.g., product characteristics, inventory levels, seasonality, special needs, applied warehousing technology in case of warehousing, etc.).

4. The Listing of possible logistics service providers: A possible logistics service providers' list can be drawn up based on databases containing company data and/or advice of external expert(s).

5. Call for bids: In this step the company will determine the description of the activity to be performed and its expectations for logistics service providers.

6. Ranking of the logistics service providers based on the received tenders: The company creates an evaluation system to rank the received tenders. Generally, the best logistics service providers are selected for follow-up examinations.

7. Evaluation of the logistics service providers at their establishment: We need to assess the selected logistics service provider(s) at their place(s) of business based on the outsourcing realization criteria (e.g., adequate expertise, enough logistics capacity, modern information technology, etc.).

8. Selection of the best logistics service provider(s): In this step we need to select the outsourcing partner(s) based on visiting the establishment(s) and the received tenders. In many cases there is necessary to apply a multi-criteria decision-making method.

II. Contractual process: This process lasts from the assignment and specification of the logistics activity to be executed to signing the contract. In this stage detailed agreements are made on the activities to be executed after the outsourcing, the expected service level (e.g., rate of accurate deliveries, rate of order fulfilment, etc.), the responsibilities of each party, as well as the payment process in case 
of proper performance. In addition, terms and conditions related to bonuses, penalties, withdrawal from the contract and other legal matters are fixed in the contract. The contractual process will be concluded by the signatures of the partners.

III. Implementation process: This process lasts from the planning of the operating process and IT support to the performance feedback. Generally, the material and information flows are planned, implemented and carried out in this process. The most important part of the process is the performance feedback, which is applied to determine the fees to be paid and the rate of reward and penalty, as well as to compare indicator value before and after the outsourcing (e.g., rate of order fulfilment, utilization of vehicle capacities, etc.).

\section{Basic Concept of the Outsourcing Investigation System Integrated in the Electronic Marketplace}

Based on our own industrial experiences [30-32], as well as analysis of the more important literature $[19,23,26,29,33,34]$ that the outsourcing examination process is normally carried out as part of the tendering process, which has the following shortcomings:

- In many cases the outsourcing examination is carried out by people who are not competent in the field, which can lead to poor selection of criteria and not the best choice of logistics service provider(s).

- No framework is available to enable the management of outsourcing throughout the total investigation process.

- The possible investigational types were not revealed and elaborated, nor were a data model, decision model or methods for the logistics service areas that could result in a quicker and more efficient examination.

To manage the revealed shortcomings, an outsourcing investigation system's basic concept integrated in an electronic marketplace was designed. The investigation model's operation can be specified for different logistics service areas. Basically, this concept provides a business model for later research.

\subsection{Possibilities and Operational Potential of the Electronic Marketplace's Creation}

We can distinguish three approaches to the electronic marketplace: consumer centric, seller centric, or intermediary. In a consumer-centric approach, the electronic marketplace is operated by a company or a consortium with significant customer potential, and the operator can purchase the necessary product(s)/service(s) at lower prices. In a seller-centric version, the electronic marketplace's is operated by a company or a consortium with relevant seller potential, and the operator can sell its product(s)/service(s) at higher prices. In an intermediary type, the operator is an independent company or consortium [35].

The intermediary model is most applicable in the fields of a logistics services outsourcing examination, because trust is very important for the system to work (we are not able to provide impartiality in the case of the consumer or the seller centric electronic marketplace).

The electronic marketplace's creation can be realized in three ways:

- creation of a new electronic marketplace,

- as a new service for an existing marketplace,

- as a new service for an existing virtual logistics enterprise.

If we would like to define the essence of the virtual logistics enterprise, then it is a group of individual enterprises that are located in different places and temporarily collaborate for an optional period while maintaining their independence [36]. This collaboration is realized by use of computer networks and optimal utilization of the logistics resources [37].

The electronic marketplace's creation mode primarily depends on the establishing company's IT infrastructure and financial possibilities. Naturally it is more economical to create the outsourcing 
investigational system as an existing electronic marketplace or virtual logistics enterprise's new service (the infrastructure that is necessary to actuate the outsourcing investigation system is partially available and probably we can reach higher utilization in case of the applied human and machinery capacities). The electronic marketplace will be workable in the long term if it is characterized by:

- A significant demand for the provided service: The customer needs and the industrial environment is continuously changing, so it is necessary to review the earlier outsourcing decision periodically. According to some case studies, outsourcing decisions are reviewed every 2-3 years [28,29]. This generates regular demand for the provided services.

- Economical operation and advantageous fees for the clients: The outsourcing examination fee is determined by the electronic marketplace's operator. The company who requires the outsourcing examination and/or the logistics service provider(s) only must pay after outsourcing process is successfully concluded, based on the operator's business policy in the interest of the operation potential's maintenance. The logistics service providers are selected, and the examined service is implemented because of the successful outsourcing process.

The following pricing possibilities can be applied for the company requesting the outsourcing examination $[20,29,38]$ :

- Open-book method: The electronic marketplace's operator provides insights into the operation's costs for the clients as an open book. The invoice is determined based on the incurred costs and the amount of profit agreed upon.

- Mutual sharing of the benefits: The examination's fee is calculated from the clients' savings based on a predefined rate (the rate is fixed in the service agreement).

- Calculated fee based on the complexity of the examination: The electronic marketplace's operator determines the fee based on the examination's complexity (e.g., length of investigational period, number of the examined products, number of examined transportation relations, etc.).

The following pricing possibilities can be applied for the logistics service providers:

- Activity based pricing: The payment for the electronic marketplace's operator is predefined pricing regarding every successful logistics activity transaction after the outsourcing process. The fees are determined based on the executed activities (e.g., number of stock-in, average storage lead time, etc.). The fee to be paid is calculated by multiplying the realized activities by the fees.

- $\quad$ Pricing based on volume of the activity to be executed: The logistics service provider pays a one-time acquisition fee to the electronic marketplace operator based on the activity to be performed (expected inventory level, transportation frequency).

- The new service provides relevant advantages compared with other solutions:

- Possible advantages of the elaborated outsourcing examination method for the companies requesting the examination:

- Experts of the electronic marketplace know the examination possibilities and the elaborated system's operational concept, and thus the company can choose the appropriate investigation alternative.

- The outsourcing examination does not require substantial human resources on the part of the client company (as the electronic marketplace's experts carry out the examination).

- The investigational lead time can be significantly reduced by following existing procedures and utilizing databases; consequently, the client company will be able to respond more flexibly to challenges of the industrial environment. 
- The offered price will become comparable because the logistics service provider will give their data in a standard data structure and predefined mode.

- Qualification of the logistics service providers' activities will be carried out by the electronic marketplace's independent experts, offering an objective decision.

- We can perform more complex decision making/optimization because of the standardized data and the larger number of examined tenders.

- It is possible for new logistics service providers to join in the electronic marketplace based on recommendations of client company and the electronic marketplace's experts.

- The outsourcing examination fees will only be paid after successful outsourcing based on the service agreement.

Possible advantages of the elaborated outsourcing examinational method for the logistics service providers:

- The logistics service providers will gain more orders through the outsourcing investigational system; consequently, their turnover will increase.

- The outsourcing examination fees will only be paid after successful outsourcing based on the service agreement.

- Possible disadvantages of the elaborated outsourcing examination method for the client companies and the logistics service providers:

- Data security risk (a confidentiality agreement is a necessary essential requirement).

\subsection{Basic Concept of Outsourcing Investigational System Integrated in Electronic Marketplace}

Figure 3 presents the elements of the logistics services outsourcing investigational system, as well as the relations between them. The electronic marketplace model can be divided into two parts: participants involved in the operation, and the most important software components (related applications, user software, database server, databases). This section fully introduces the basic concept's participants and the relations between them.

The electronic marketplace's participants:

- E-management: Its task is to make strategical and tactical decisions about the operation of the electronic marketplace. Its other tasks are to make development decisions based on discussions with the R \& D team, form contracts, carry out accession negotiations with new logistics providers and production companies according to the experts' proposals.

- $R \mathcal{E} D$ team: The research and development team's task is increasing the operational potential of the electronic marketplace by implementing the company's management's improvement decision.

- Experts: The experts know operational algorithms and software of the electronic marketplace outsourcing investigational system. Their main tasks are introducing the outsourcing investigation alternatives to the clients, data collection, data processing and evaluation tasks related to the outsourcing examination. Other tasks are to upload the collected data to the proper database through a switch program. In addition, they are responsible for exploring further logistics providers and production companies using central search algorithms/programs [39] and/or information providers' databases.

- Information providers: These companies provide additional information for execution of the outsourcing examination. The provided information can be data such as the delivery route's length and duration between the electronic marketplace's objects (warehouses, customers, establishments, etc.). Furthermore, their tasks may include giving data of logistics providers and their services in accordance with the experts' needs (e.g., logistics providers dealing with warehousing activities in a district). 
- Logistics service providers: These companies join in the electronic marketplace to improve the utilization of their logistics capacity and increase their revenue. Their task is to make offers(s) offered through the LS switch program according to the received data and to provide the necessary information for the electronic marketplace's experts. They have a possibility to modify the offered price(s) through the LS switch program.

- Production companies: Participants who temporarily join in the electronic marketplace because of execution of an outsourcing examination to select the best logistics service provider(s) for the assigned logistics service(s). They are responsible for providing data to experts about the logistics service to be examined, as well as making the proper decisions corresponding to the company's aim. They have the opportunity to view and modify their own data through the P switch program. The experts perform the required modifications according to the production company's needs.

- Bank: It manages the revenue from the production companies and/or logistics service providers for the completed outsourcing examination.

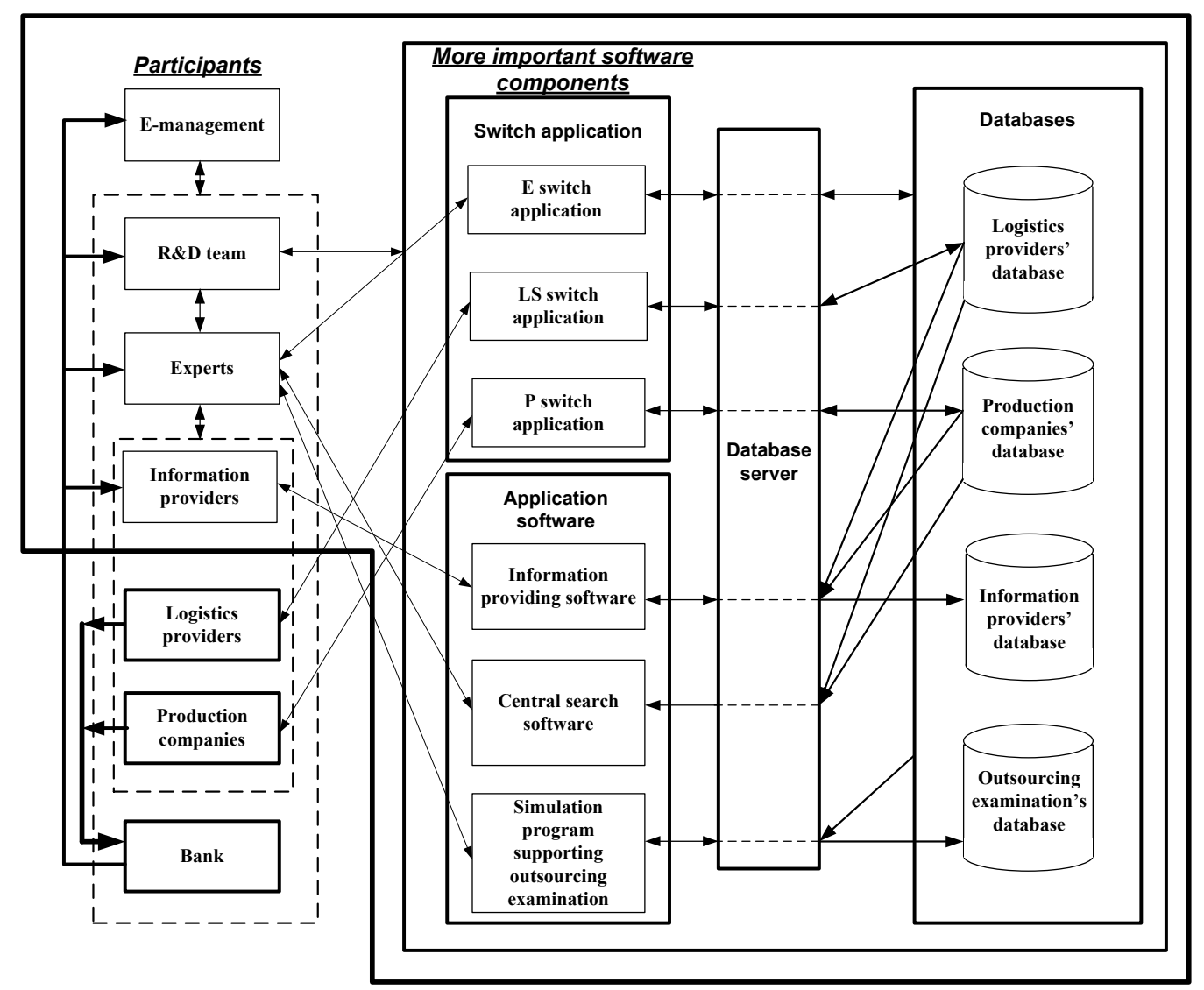

Figure 3. Basic Concept of Outsourcing Investigation System Integrated in an Electronic Marketplace.

Switch application of the electronic marketplace:

- P switch application: This application enables bidirectional communication between the production companies and their database, which includes the view and modification of data uploaded.

- LS switch application: The application implements bidirectional communication between the logistics service providers and their database, so they can query and modify the data uploaded (provided service's data, offered price).

- E switch application: This application implements the bidirectional communication between the experts and the databases of the electronic marketplace. It is responsible for uploading data 
regarding the production and service companies by the experts. In addition, any kind of queries and updates can be carried out through this application.

Software of the electronic marketplace:

- Information providing software: Its task is to define the estimated transport distance and duration matrix between outsourcing examination's objects (e.g., establishments, warehouses, customers, suppliers, etc.) based on their GPS coordinates. The information providers upload their data in the information providers' database using this application.

- Central search software: Its task is to look for new members based on the databases of logistics providers and production companies to join in the electronic marketplace in the interest of more efficient decisions.

- Simulation program supporting outsourcing examination: The experts can use this program on their computers through an internet connection. A database server provides the required data for its operation. Uploading the databases takes place through previously described switch applications.

- Database server: It is responsible for permanent storage of data as well as servicing data for switch applications.

Database of electronic marketplace supporting outsourcing examination: We have defined four kinds of databases regarding the elaborated electronic marketplace, namely the databases of the production companies, logistics service providers, information services and the outsourcing examination. The data structures must be formed based on the logistics services to be examined and investigation possibilities.

Databases to be created are the following:

- Logistics provider database: This database includes the examined logistics service's most important data in terms of the outsourcing.

- Production company database: The database contains the logistics service providers' data about the data of service to be provided.

- Information provider database: This database is uploaded by information providers. The typical data are distance, duration, etc.

- Outsourcing examination database: This database includes the conditions and objective functions, as well as the created data of the simulation program which are necessary to execute the outsourcing examination.

\subsection{Operational Process of Electronic Marketplace Supporting Oursourcing Examination}

The outsourcing examination system's steps are the following (Figure 4):

1. Establishment of contact: The clients look for the electronic marketplace's experts and/or the experts look for the clients for the outsourcing examination.

2. Selection of the logistics service to be examined: The electronic marketplace's expert(s) and the production company's representative(s) determine the logistics service(s) to be examined in aspect of the outsourcing.

3. Determining the mode of the outsourcing examination: The electronic marketplace's expert(s) and the production company's representative(s) specify the outsourcing examination (length of the investigational period, useable data, scope of the logistics service providers to be evaluated, fee of the examination, etc.).

4. Signature of the agreement with the production company: The company requesting the outsourcing examination and the electronic marketplace's representative sign the service agreement that contains the details about the outsourcing examination.

5. Uploading the production company's data: The experts upload the data through the E switch application, while the production companies upload their data through the $\mathrm{P}$ switch to be outsourced. The share of the data upload is defined based on common agreement. 
6. Searching for new logistics service providers: The electronic marketplace's experts look for new logistics service providers to permit more efficient examination. The central search application (which determines the central object's coordinates based on the least material handling performance) is applied in many cases.

7. Signing of the agreement with the logistics service provider: The potential logistics service provider and the electronic marketplace's representative sign the service agreement, which contains the details about the data recording and the payment.

8. Uploading the logistics service provider's data: The experts upload the provided logistics service's data through the E switch application, while the logistics service provider(s) upload their data through the LS switch. The share of the data upload is defined based on common agreement.

9. Uploading the information provider's data: The information providers determine and upload any additional data for outsourcing examination (e.g., distance between the examined objects).

10. Setting the investigational parameters: The company requesting the outsourcing examination and the electronic marketplace's experts set the investigational data for selecting the logistics service provider(s) (type of the examination, investigational conditions, objective functions, logistics service providers to be examined).

11. Making the outsourcing decision: The best logistics service provider(s) is/are selected by a simulation application based on the uploaded data in the databases.

12. Payment for the electronic marketplace: The outsourcing examination's fee is transferred from the company requiring the outsourcing examination and/or logistics service provider to the electronic marketplace in the case that the examination was successful. The service agreement contains the fees to be transferred.

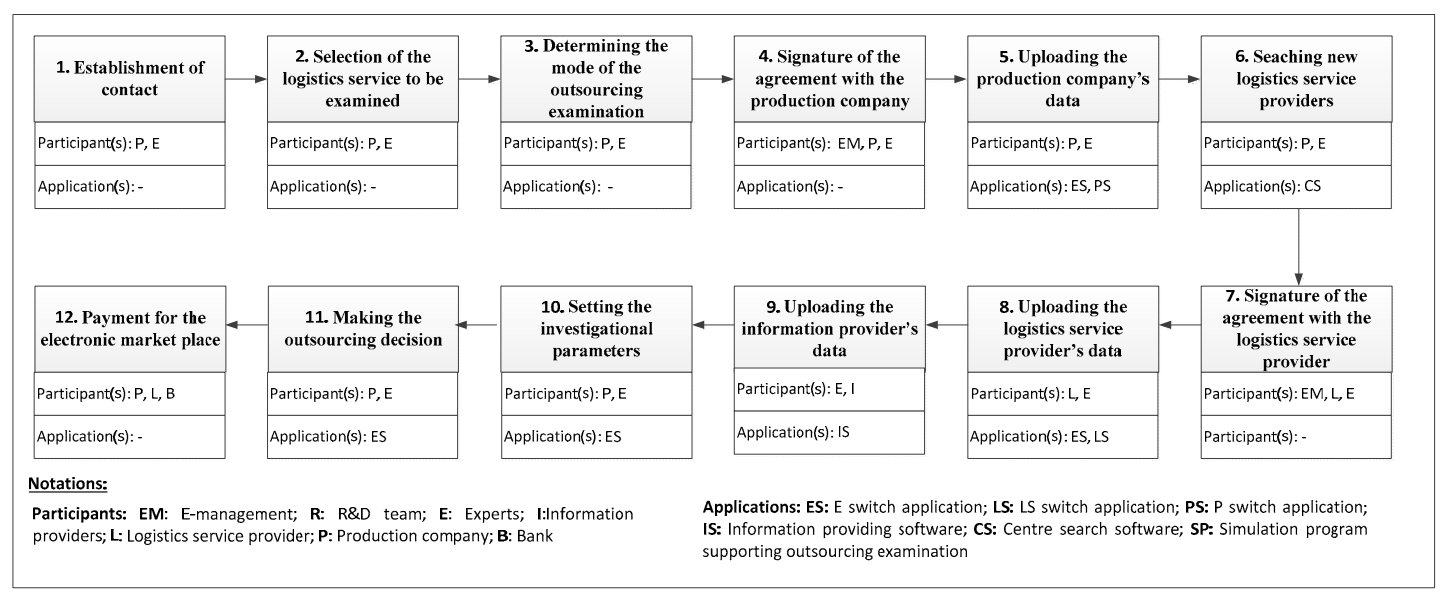

Figure 4. Operational process of electronic marketplace supporting outsourcing examination.

\section{Conclusions}

The paper has introduced the current situation of outsourcing examination and the most important possibilities for improvement in logistics services. The possibilities follow from the fact that the outsourcing investigation process is generally carried out without the support of experts, deeper analysis, or decision-making and optimization methods. Inappropriate outsourcing of logistics services has a significant role on their operational efficiency. In such a case more, resources are needed for the same logistics service to be performed; consequently, the environmental burden and extraction of non-renewable natural resources will be greater than with the optimal outsourcing. The concept of the outsourcing investigational system integrated in an electronic marketplace provides a new business model which can be advantageous for the company requiring the outsourcing examination, the logistics service provider(s), and the electronic marketplace operator as well. More efficient assignment can 
be achieved between the logistics services of companies requiring the outsourcing examination and the resources of the logistics service providers. This can result in lower costs and/or higher service levels for the companies requiring the outsourcing examination and more contracts for the logistics service providers.

We can examine new examination possibilities and carry out the outsourcing examination with a lower lead time using the elaborated concept. Further research activities include the realization of the assigned logistics services' adaptation according to the elaborated business model through the development of data models, decision making and optimization methods, as well as web-based applications.

Acknowledgments: The described research was carried out as part of the EFOP-3.6.1-16-00011 "Younger and Renewing University-Innovative Knowledge City-institutional development of the University of Miskolc aiming at intelligent specialization" project implemented in the framework of the Szechenyi 2020 program. The realization of this project is supported by the European Union, co-financed by the European Social Fund.

Conflicts of Interest: The author declares no conflicts of interest.

\section{References}

1. Benias, N.; Markopoulos, A.P. A review on the readiness level and cyber-security challenges in Industry 4.0. In Proceedings of the 2nd ACM SEEDA-CECNSM Conference 2017, Kastoria, Greece, 23-25 September 2017; pp. 76-80.

2. Tamás, P.; Illés, B.; Dobos, P. Waste reduction possibilities for manufacturing systems in the industry 4.0. In Proceedings of the IOP Conference Series: Materials Science and Engineering, Singapore, 13-15 October 2016; Volume 161, pp. 1-8.

3. Young, D.; Hawkins, T.; Ingwersen, W.; Lee, J.; Ruiz-Mercado, G.; Sengupta, D.; Smith, R.L. Designing sustainable supply chains. Chem. Eng. Trans. 2012, 29, 253-258.

4. Vervest, P.; Heck, E.; Preiss, K.; Pau, F. Smart Business Networks; Springer: Berlin/Heidelberg, Germany, 2005; pp. 159-167. ISBN 3-540-22840-3.

5. Franceschini, S.; Faria, L.G.D.; Jurowetzki, R. Unveiling scientific communities about sustainability and innovation. A bibliometric journey around sustainable terms. J. Clean. Prod. 2016. [CrossRef]

6. Womack, J.P.; Jones, D.T. Lean Thinking; Simon \& Schuster Inc.: New York, NY, USA, 2008.

7. Rother, M.; Shook, J. Learning to See: Value Stream Mapping to Add Value and Eliminate Muda; Lean Enterprise Institute: Cambridge, MA, USA, 2003.

8. Tyagi, S.; Choudhary, A.; Cai, X.; Yang, K. Value stream mapping to reduce the lead-time of a product development process. Int. J. Prod. Econ. 2015, 60, 202-212. [CrossRef]

9. Fruggiero, F.; Riemma, S.; Ouazene, Y.; Macchiaroli, R.; Guglielmi, V. Incorporating the Human Factor within Manufacturing Dynamics. IFAC-PapersOnLine 2016, 49, 1691-1696. [CrossRef]

10. Fera, M.; Fruggiero, F.; Lambiase, A.; Macchiaroli, R.; Miranda, S. The role of uncertainty in supply chains under dynamic modeling. Int. J. Ind. Eng. Comput. 2017, 8, 119-140. [CrossRef]

11. Martino, G.; Fera, M.; Iannone, R.; Miranda, S. Supply Chain Risk Assessment in the Fashion Retail Industry: An Analytic Network Process Approach. Int. J. Appl. Eng. Res. 2016, 12, 140-154.

12. Martino, G.; Fera, M.; Iannone, R.; Miranda, S. Proposal of a Multi-method Decision Support System for the Fashion Retail Industry. In Lecture Notes in Electrical Engineering-Business Models and ICT Technologies for the Fashion Supply Chain; Springer: Berlin, Germany, 2016; Volume 413, pp. 187-194.

13. Frazelle, E. World-Class Warehousing and Material Handling; McGraw Hill Professional: New York, NY, USA, 2001; ISBN 0-07-137600-3.

14. Lynch, C.F. Logistics Outsourcing: A Management Guide; Council of Logistics Management Publications: Chicago, IL, USA, 2000.

15. Ali, K.; Erman, C.; Turan, Ç. Factors to Consider for Outsourcing Decision in Supply Chain Management. In Proceedings of the 4th International Logistics and Supply Chain Congress, Turkey, Izmir, 29 November-1 December 2006.

16. Marasco, A. Third-party logistics: A literature review. Int. J. Prod. Econ. 2008, 113, 127-147. [CrossRef]

17. Cselényi, J.; Illés, B. Logistics Systems I; University of Miskolc: Miskolc, Hungary, 2004. 
18. Tamás, P.; Kovács, G.; Illés, B. Outsourcing examination for finished goods storage activity with electonic marketplace. Adv. Logist. Syst. 2011, 5, 71-75.

19. Metz, M. Outsourcing von Logistiksleistungen. Tech. Rundschau. 1998, 90, 72-75.

20. Nyári, K.; Laurent, C. Logistics outsourcing in the retail-outsourcing or insourcing. In Hungarian Logistics Association, Logistic Annual Book; Hungarian Logistics Association: Budapest, Hungary, 2005.

21. Tsai, W. Outsourcing or capacity expansions, Applications of activity-based costing model on joint products decision. Comput. Oper. Res. 2007, 34, 3666-3681. [CrossRef]

22. Agnieszka, K. Outsourcing as the Conception of Modern Management, The Challenges for Reconversation, Innpvation-Sustainability-Knowledge Management; Advanced Logistics Systems: Chestochowa, Poland, 2006.

23. Tompkins, J.A.; Smith, J.D. The Warehouse Management Handbook; Tompkins Press, Mcgraw-Hill: New York, NY, USA, 1988; pp. 63-88. ISBN 0-9658659-1-6.

24. Kim, S.; Yang, D.; Nam, C.; Min, J. Developing a decision model for business process outsourcing. Comput. Oper. Res. 2007, 34, 3769-3778.

25. Teyarachakul, S.; Tang, K.; Tarakci, K. Learning effects on maintenance outsourcing. Eur. J. Oper. Res. 2007. [CrossRef]

26. Simoni, B.; Huber, E. Logistik-Outsourcing Mit System-Dritte Richtig Auswählen, Schweizer Maschinenmarkt, 100. k. 15. sz., 1999. pp. 16-21. Available online: https:/ / www.maschinenmarkt.ch/ (accessed on 10 January 2018).

27. Tanács, Z. Basics of the Successful Outsourcing: Adequate Preparation of the Outsourcing Decision; IME: Kathmandu, Nepal, 2002; Volume 1.

28. CAPGEMINI CONSULTING KFT. Third-Party Logistics 2008-Results and Findings of the 13th Annual Study; CAPGEMINI CONSULTING KFT: Paris, France, 2008.

29. KPMG Ltd. Logistics Outsourcing in Hungary; Case Study; KPMG Ltd.: Amstelveen, The Netherlands, 2009.

30. Tamás, P.; Cselényi, J.; Bálint, R. Decision supporting model and method for outsourcing of distribution logistics system of paper factories. In Proceedings of the 4th International Logistics and Supply Chain Congress, Turkey, Izmír, 29 November-1 December 2006; pp. 271-277.

31. Tamás, P.; Cselényi, J.; Bálint, R. Mathematical models for outsourcing of delivery channels of paper industry company. In Proceedings of the Miskolcer Gespräche, Miskolc, Hungary, 13-14 September 2006; pp. 230-239.

32. Tamás, P.; Cselényi, J. Alternatives for outsourcing possibilities of finished goods storage activity of production companies. In Proceedings of the International Scientific Conference microCad 2007, Miskolc, Hungary, 22-23 March 2007; pp. 101-110.

33. Agrawal, S.; Goswami, K.; Chatterjee, B. The Evolution of Offshore Outsourcing in India. Glob. Bus. Rev. 2010, 11, 239. [CrossRef]

34. Hätönen, J.; Eriksson, T. 30+ years of research and practice of outsourcing-Exploring the past and anticipating the future. J. Int. Manag. 2009, 15, 142-155.

35. Kacsukné, B.L.; Cselényi, J. On the Optimization Problems of Emmil Marketplaces. In Proceedings of the microCAD International Conference, Miskolc, Hungary, 10-11 March 2005.

36. Scholz, C. Die Virtuelle Organisation als Strukturkonzept der Zukunft?; Universität des Saarlandes Saarbrücken, Lehrstuhl für Betriebswirtschaftslehre, Studie: Saarbrücken, Germany, Unpublished work. 1994.

37. Kacsukné, B.L. Algorithms for E-Marketplaces Integrated with Logistics. Prod. Syst. Inf. Eng. 2006, 3, 3-20.

38. Lakatos, P. Planning and Realization of the Logistics Outsourcing at the Tesco Global Corp.; Logistics Annual Book; Tesco Global Corp.: Houston, TX, USA, 2001; pp. 87-92.

39. Cselényi, J.; Illés, B. Planning and Controlling of Material Flow Systems; University of Miskolc: Miskolc, Hungary, 2006.

(C) 2018 by the author. Licensee MDPI, Basel, Switzerland. This article is an open access article distributed under the terms and conditions of the Creative Commons Attribution (CC BY) license (http://creativecommons.org/licenses/by/4.0/). 